\title{
Augmentative role of Piriformospora indica fungus and plant growth promoting bacteria in mitigating salinity stress in Trigonella foenum-graecum
}

\author{
Sanskriti Bisht ${ }^{1}$, Shatrupa Singh ${ }^{1}$, Madhulika Singh ${ }^{1,2}$, Jai Gopal Sharma ${ }^{1 *}$ \\ ${ }^{1}$ Department of Biotechnology, Delhi Technological University, Delhi, India. \\ ${ }^{2}$ Department of Botany, SSN College, University of Delhi, Delhi, India.
}

\begin{tabular}{l}
\hline ARTICLE INFO \\
\hline Article history: \\
Received on: April 21, 2021 \\
Accepted on: July 14, 2021 \\
Available online: January 07, 2022 \\
\hline
\end{tabular}

\section{Key words:}

Photosynthesis, stomatal conductance, transpiration, internal $\mathrm{CO}_{2}$, carotenoids, chlorophylls, protein, nitrogen

\begin{abstract}
An experiment was conducted to evaluate the role of Piriformospora indica and plant growth promoting bacteria (PGPB) in mitigating salinity stress in Trigonella foenum graecum. Plants were subjected to three different levels of salinity, viz., 0,70 , and $150 \mathrm{mM} \mathrm{NaCl}$ (electrical conductivity value $0.01,7.67$, and 15.50 $\mathrm{mS} \mathrm{cm}{ }^{-1}$, respectively) using a completely randomized design experiment. The $P$. indica and PGPB showed positive effects in mitigation of salinity stress in fenugreek plants and elevated various growth responses, viz., shoot and root length, shoot and root dry weight, leaf area, and number of leaves as compared to uninoculated plants. Microbial inoculation significantly enhanced the physiological responses, viz., photosynthetic rate, stomatal conductance, transpiration and internal $\mathrm{CO}_{2}$ as compared to uninoculated plants. Biochemical aspects like carotenoids, chlorophylls, nitrogen, and protein content were also increased in the microbial inoculated plants as compared to uninoculated plants. However, PGPB was more effective than $P$. indica in mitigating salinity stress in fenugreek plant. The findings of this study revealed that $P$. indica and PGPB inoculation can help the plants to overcome the deleterious effects of salinity stress in fenugreek plants.
\end{abstract}

\section{INTRODUCTION}

World agriculture is facing a crucial challenge of meeting the food demand of rising global population, which is currently growing at around $1 \%$ per year world population prospects revision. Several biotic and abiotic stresses have a significant impact on the growth productivity, yield, and food quality of plants [1,2]. Damages or diseases caused by a variety of pests or pathogens are referred to as biotic stresses, whereas salinity, rising temperatures, declining freshwater supplies, heavy metals, and other chemical pollutants are example of abiotic stresses which necessitate an integrated solution, collective intervention and extensive research in order to combat these stresses [3].

Soil salinity is one of the most harmful stress among all the abiotic stresses [4]. Salinization of agricultural land happen

\footnotetext{
*Corresponding Author

Jai Gopal Sharma, Department of Biotechnology, Delhi Technological

University, Delhi, India.E-mail: sharmajaigopal @gmail.com
}

mainly because of the deposition of salt ions in soil (chlorides, sulphates, nitrates, calcium, sodium, potassium, and magnesium) [5] and is viewed as the most significant constraints on agricultural production and food security since crops react to soil salinity in a variety of ways and while growing in salinity conditions these factors completely influence their ability to sustain and achieve a sufficient amount of production [6]. $\mathrm{NaCl}$ is the most common salt found in soils which hampers soil water conductance, porosity, and aeration $[7,8]$. Salinity affects over $20 \%$ of agricultural land worldwide [9]. An estimate number of 6.7 million hectares of land in India is also salt affected with Gujarat having the largest volume of almost $71 \%$ of the overall salty soils in India.

Horticultural crops (spinach, potatoes, tomatoes, and lettuce) and cereals (maize, wheat, rice, and legumes) are sensitive to salinity stress which reduces the yield up to $50 \%-75 \%$ [5]. A plant that is under the influence of salt stress goes through series of morphological, physiological, and molecular modifications, eventually obstructing its maturation [10]. Photosynthesis is affected by soil salinity, which results in a reduction in leaf area. With extended salt tension, old 
leaves begin to experience chlorosis, and hence collapse. If the rate at which leaves die outpaces the rate at which they are formed, the plant's photosynthetic ability would be unable to provide the needed carbohydrate to young leaves, resulting in a drastic reduction in their developmental rate [11]. Photosynthesis is affected by salinity in both the short- and long-term stresses. Short-term salt stress is very quick and happens within a short period of salt exposure so it leads to reduced carbon assimilation by affecting stomatal limitations in photosynthesis, whereas the long-lasting affect is that the salt starts to accumulate in young leaves [12], this reduces the amount of chlorophyll and carotenoids and changes in the lipid-protein ratio of pigment-protein complexes or even increased chlorophyllase activity may cause a decrease in chlorophyll content [13]. The chloroplast's thylakoid forms also become disordered as they are exposed to salt and the number and size of plastoglobuli increases as well. Salt stress is also observed to affect the stomata size and the density, leading to the reduction of stomatal conductance [14]. Plants that are subject to high salt concentrations have smaller and faded leaves [5].

Salinity stress also promotes the formation of reactive oxygen species, which cause damage to cell membrane, proteins, lipids and nucleic acids, as well as programmed cell death [1]. Many studies have revealed that the transgenic plants mitigate salt stress [15], yet these methods happen to be high-priced and time consuming [16]. Microbes are less expensive and have tremendous stressrelieving capacity [17]. Plant microbial association boosts the plant growth and production under salt stress [18]. Brevibacterium epidermidis, Micrococcus yunnanensis, and Bacillus aryabhattai were found to increase root elongation and dry weight in canola [19]. Since saline ecosystems have insufficient nitrogen, nitrogen input is needed in these conditions [20]. Funneliformis mosseae and Diversispora versiformis inoculation increased the nitrogen uptake in Chrysanthemum morifolium plant under salt tension thereby, enhancing shoot and root length, and dry weight. The role of Bacillus amyloliquefaciens has been confirmed to improve chlorophyll content in maize seedling under salinity stress [21]. Massilia sp. and co-culture of Rhizophagus intradices have improved the nitrogen in maize shoots dramatically [22]. Pseudomonas putida inoculation in soyabean plant increased the shoot length, chlorophyll content, fresh and dry weight of plant [23]. Under high salt conditions, the photosynthetic pigment content was substantially increased in Piriformospora indica inoculated rice seedlings. Brachybacterium saurashtrense, Brevibacterium casei, and Haerero halobacter increased total biomass in Arachis hypogea [24].

Salt tolerance has been identified in host plants provided by plant growth promoting bacteria (PGPB) which helped the plants' ability to survive in adverse situations [25]. Crops grown in saline environments can benefit from mutual symbiosis with beneficial entophytic fungi to alleviate salt stress and yield loss [26]. Growth and biomass in curcuma were improved by $P$. indica inoculation [8]. Fenugreek is one of the most chief cash crops of India. It is a dicotyledonous annual herb used as vegetable and forage. The seeds (whole, ground, in flour, or roasted) are used as human and animal food, as well as for industrial and medicinal purposes [27]. The fenugreek plant growth and productivity are severely affected by salinity. Very few reports are there on the role of microbes in alleviating salinity stress in fenugreek. In this experiment, we analyzed the beneficial role of PGPB and P. indica association in fenugreek plants during salinity stress.

\section{MATERIALS AND METHODS}

\subsection{Plant Material and Experimental Design}

Fenugreek seeds were obtained from national seeds corporation, IARI, New Delhi, India. Experiment was conducted in the Department of Horticulture, Delhi Technological University, Delhi, India. The $3 \times 6$ factorial experiment was designed for $P$. indica and PGPB with two conditions: microbial inoculated or uninoculated with three salinity levels $(0,70$, and $150 \mathrm{mM} \mathrm{NaCl})$. Thus, eighteen combinations were set up in randomized full block configuration in a replicate of three.

\subsection{Microbial Inoculation, Soil, and Salt Treatments}

Soil was inoculated with $P$. indica and PGPB (Azotobacter chroococcum, Enterobacter asburiae, and Lactococcus lactis) at the time of sowing. In non-inoculated plants, same amount of sand was added. Eight sterilized seeds were sown at a depth of $3 \mathrm{~cm}$ in each plastic pot having $4 \mathrm{~kg}$ of an autoclaved $\left(121^{\circ} \mathrm{C}\right.$ and 15 psi) sandy loam soil. The soil had a $\mathrm{pH}$ : 7.2, organic matter: $1.3 \%$, available $\mathrm{N}$ : $185 \mathrm{mg} \mathrm{g}^{-1}$, available P: $49.4 \mathrm{mg} \mathrm{g}^{-1}$, available $\mathrm{K}^{+}$: $295 \mathrm{mg} \mathrm{g}^{-1}, \mathrm{Mg}^{2+}: 230 \mathrm{mg} \mathrm{g}^{-1}, \mathrm{Zn}^{2+}: 6.8 \mathrm{mg} \mathrm{g}^{-1}, \mathrm{Fe}^{3+}: 11.9 \mathrm{mg}$ $\mathrm{g}^{-1}, \mathrm{Cu}^{2+}: 3.99 \mathrm{mg} \mathrm{g}^{-1}, \mathrm{Mn}^{2+}: 6.98 \mathrm{mg} \mathrm{g}^{-1}$. The plants were grown in greenhouse conditions (Temperature: $23^{\circ} \mathrm{C}-28^{\circ} \mathrm{C}$; relative humidity: $65 \% \pm 5 \%$, and light intensity: 1,500 lux). Salt treatment began following 15 days of plant development. To each pot, $50 \mathrm{ml}$ of $\mathrm{NaCl}$ solution was added sequentially after 7 days to avoid any osmotic shock to the roots till 45 days after sowing. In control, $50 \mathrm{ml}$ of distilled water was added in each pot till 45 days after sowing. Upon addition of $\mathrm{NaCl}$ solution, the electrical conductivity (EC) of soil extracts increased to $0.01,7.67$, and $15.50 \mathrm{mS} \mathrm{cm}$ in the 0,70 , and $150 \mathrm{mM} \mathrm{NaCl}$ salinity levels, respectively. The electrical conductivity (EC) of the soil was determined by using conductivity meter (HACH analyzer, HQ440d). Autoclaved tap water was used for irrigating the plants twice in a week (Fig. 1). Plants were harvested by uprooting the entire plant manually after 45 days of sowing.

\subsection{Shoot and Root Length Measurement}

The plants were harvested 45 days after sowing. To eliminate any sticking particles, the root and shoot were rinsed thoroughly with tap water and blotted dry. Lengths of root and shoot were measured immediately using a scale.

\subsection{Biomass Measurement}

The fresh plant leaves were wrapped separately in blotting paper and kept in oven for 72 hours at $75^{\circ} \mathrm{C}-80^{\circ} \mathrm{C}$ to record the dry biomass. Dry weights were measured using weighing balance.

\subsection{Leaf Area and Number of Leaves Measurement}

The numbers of leaves were counted. Leaf area measurement was performed using leaf area meter (CID Bio-sciences, CI-202 Laser area meter). 


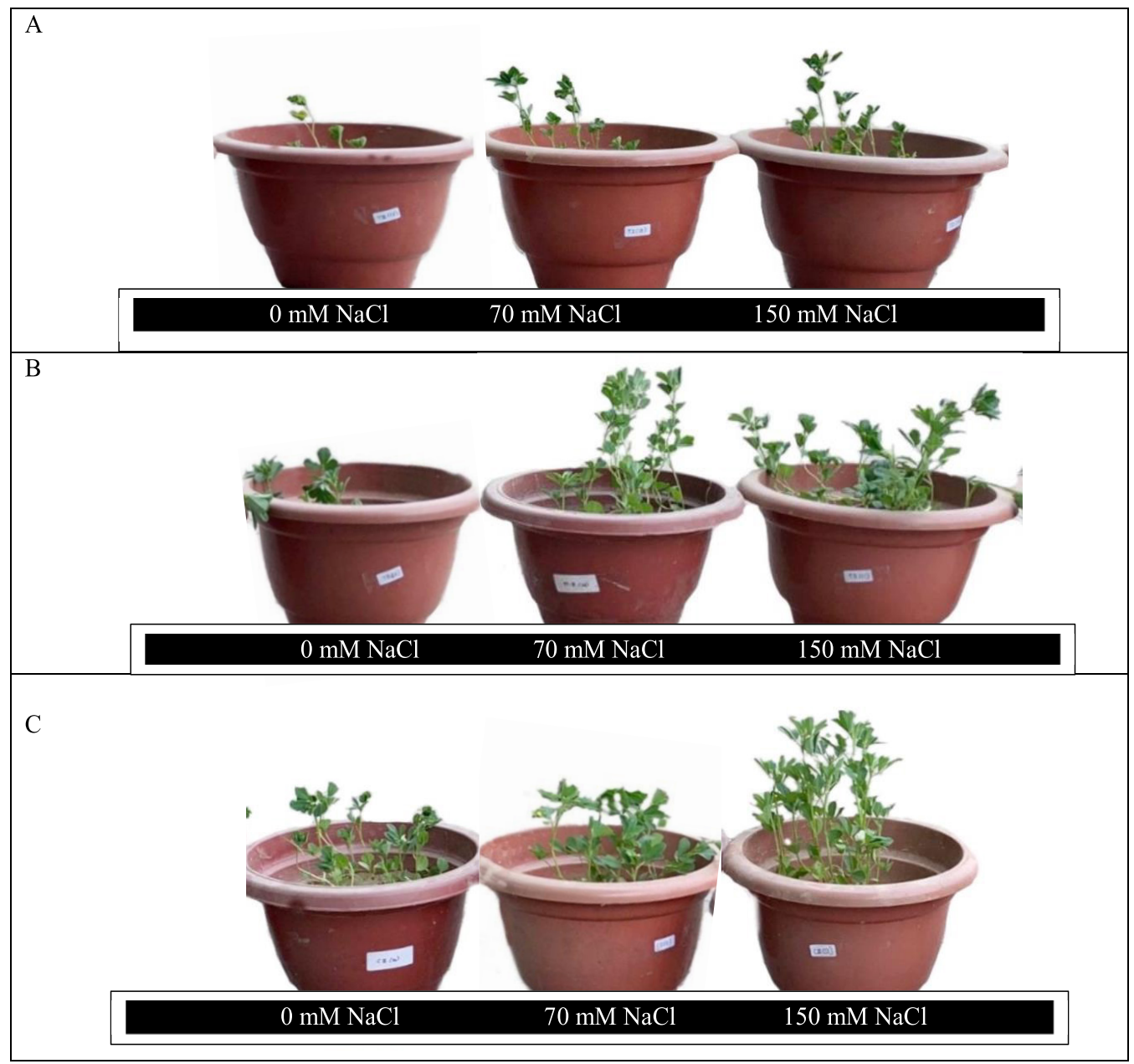

Figure 1: Experimental set up showing (A) uninoculated (B) P. indica inoculated (C) PGPB inoculated plants after 45 days of sowing.

\subsection{Photosynthesis Rate, Stomatal Conductance, Transpiration, and Internal $\mathrm{CO}_{2}$ Measurement}

Physiological parameters (photosynthesis, stomatal conductance, transpiration, and internal $\mathrm{CO}_{2}$ ) were measured by portable photosynthesis system (Li-6400XT Infra-red gas analyzer).

\subsection{Photosynthetic Pigments Estimation}

The content of chlorophylls and carotenoids in plant leaves were estimated according to Hiscox and Isradtom [28] protocol. Fresh leaflets $(0.1 \mathrm{~g})$ were chopped down into small slices and put into a vial having $7 \mathrm{ml}$ dimethyl sulfoxide (DMSO). The leaf tissue in the vials was incubated at $65^{\circ} \mathrm{C}$ until it turned white. The extracts were transferred to a tube and DMSO was used to make up $10 \mathrm{ml}$ of total volume. The extract's absorbance was measured at 645 and $663 \mathrm{~nm}$ for chlorophyll content, 480 and $510 \mathrm{~nm}$ for carotenoid content, and the concentration of chlorophyll and carotenoid was measured using the formulas, respectively [28].

Chlorophyll a $(\mathrm{mg} / \mathrm{g}$ fresh weight $)=\left[\left(12.7 \times \mathrm{D}_{663}\right)-\left(2.69 \times \mathrm{D}_{645}\right)\right]$ $\times($ Volume $/ 1000 \times$ Weight of sample $)$

Chlorophyll b $(\mathrm{mg} / \mathrm{g}$ fresh weight $)=\left[\left(22.9 \times \mathrm{D}_{645}\right)-\left(4.68 \times \mathrm{D}_{663}\right)\right]$ $\times($ Volume $/ 1000 \times$ Weight of sample $)$
Total chlorophyll $(\mathrm{mg} / \mathrm{g}$ fresh weight $)=\left[\left(20.02 \times \mathrm{D}_{645}\right)+(8.02 \times\right.$ $\left.\left.\mathrm{D}_{663}\right)\right] \times($ Volume $/ 1000 \times$ Weight of sample $)$

Carotenoid $(\mathrm{mg} / \mathrm{g}$ fresh weight $)=\left[\left(7.6 \times \mathrm{D}_{480}\right)-(1.49 \times \mathrm{D} 510)\right] \times$ ( Volume/1000 $\times$ Weight of sample)

\subsection{Nitrogen and Protein Estimation}

The determination of nitrogen and protein was done according to the protocol of FOSS Kjeldahl block digestion and steam distillation (AN 300, EN ISO 20483:2006) [29]. To $0.7 \mathrm{~g}$ dried powdered leaf sample, $7 \mathrm{~g} \mathrm{~K}_{2} \mathrm{SO}_{4}, 0.8 \mathrm{~g} \mathrm{CuSO}_{4}$, and $12 \mathrm{ml}$ concentrated $\mathrm{H}_{2} \mathrm{SO}_{4}$ were added. Digestion was performed on kjeldahl digester unit (FOSS company) for 60 minutes at $420^{\circ} \mathrm{C}$. Distillation was performed using fully automated distillation unit (kjeltec 8200, FOSS) [29]. To the receiver flask, $30 \mathrm{ml}$ of $4 \%$ boric acid (receiver solution) was added and to the digested sample $80 \mathrm{ml}$ Milli Q water and $50 \mathrm{ml} 40 \% \mathrm{NaOH}$ was added. Distillate was titrated with standardized titrant (0.1 N HCL) using burette (Eppendorf bottle-top digital burette). Reagent blank was performed out earlier to every set of samples. Nitrogen and protein content was obtained using the formula:

$$
\% N=(T-B) \times N \times 14,007 \times 100 / \text { weight sample }(\mathrm{mg})
$$


$T=$ Sample titration $B=$ Blank titration; $N=$ Normality of titrant

$$
\begin{gathered}
\% \text { Protein }=N \times F \\
F=6.25 \text { for fenugreek }
\end{gathered}
$$

\subsection{Statistical Analysis}

The data were analyzed using SPSS 21 statistical programme (IBM SPSS Statistics 21) by one way analysis of variance with $\mathrm{NaCl}$ treatment, microbial inoculation, and interactions among them as a source of variation. Comparison of the means were determined by post hoc Duncan's test $(p<0.05)$.

\section{RESULTS}

\subsection{Shoot and Root Length}

As the levels of salinity increased, there was a gradual increase in the shoot and root length in microbial inoculated and uninoculated fenugreek plants. However, inoculation of microbes has significantly increased shoot and root length as compared to uninoculated plants at all salinity levels. PGPB inoculated plants showed better results than $P$. indica in terms of number of shoot and root length. The shoot length in PGPB inoculated plants showed an increase by $22.96 \%$ and $56.54 \%$ at $70 \mathrm{mM}$ and 150 $\mathrm{mM} \mathrm{NaCl}$ concentrations, respectively, whereas $P$. indica showed an increase by $11.38 \%$ and $48.57 \%$ at $70 \mathrm{mM}$ and $150 \mathrm{mM} \mathrm{NaCl}$ concentrations, respectively, as compared to uninoculated plants (Fig. 2A). The root length was increased by $4.8 \%$ and $12.57 \%$ in $P$. indica inoculated plants at $70 \mathrm{mM}$ and $150 \mathrm{mM} \mathrm{NaCl}$ concentrations, respectively, as compared to uninoculated plants. PGPB which showed increase by $7.57 \%$ and $29.63 \%$ at $70 \mathrm{mM}$ and $150 \mathrm{mM} \mathrm{NaCl}$ concentrations, respectively as compared to uninoculated plants (Fig. 2B).

\subsection{Biomass}

Remarkable positive results were shown by $P$. indica and PGPB in elevating the shoot and root dry weight as compared to uninoculated plants. However, the results showed that PGPB inoculated plants have better impact than $P$. indica in elevating the shoot and root dry weight. At $150 \mathrm{mM}$ and $70 \mathrm{mM} \mathrm{NaCl}$ treatment, the increase in the shoot dry weight was by $18.51 \%$ and $190.9 \%$, respectively, in $P$. indica inoculated plants as compared to uninoculated plants (Fig. 3A). PGPB showed increase by $55.55 \%$ and $209 \%$ at 150 $\mathrm{mM}$ and $70 \mathrm{mM}$, respectively, as compared to uninoculated plants. Root dry weight was increased remarkably in PGPB by $110.86 \%$ and $207.01 \%$ at 150 and $70 \mathrm{mM} \mathrm{NaCl}$ concentrations, respectively (Fig. 3B). At 70 and $150 \mathrm{mM} \mathrm{NaCl}$ treatment the increase in the root dry weight was by $50.87 \%$ and $25 \%$, respectively, in P. indica inoculated plants as compared to uninoculated plants. Overall microbial inoculation contributes in the increase of shoot and root dry biomass as compared to the uninoculated plants.

\subsection{Number of Leaves and Leaf Area}

Under salinity stress, there was a significant difference in the number of leaves and leaf area between microbial inoculated and uninoculated plants. Microbial inoculated plants showed significant increase in the number of leaves and leaf area as compared to uninoculated plants. However, PGPB inoculated plants showed better results than $P$. indica in terms of number of leaves and leaf area. The number of leaves in PGPB inoculated plants showed an increase by $78.32 \%$ and $37.22 \%$ at $70 \mathrm{mM}$ and $150 \mathrm{mM} \mathrm{NaCl}$ concentrations, respectively, whereas $P$. indica showed an increase by $65.2 \%$ and $20 \%$ at $70 \mathrm{mM}$ and $150 \mathrm{mM} \mathrm{NaCl}$ concentrations, respectively, as compared to uninoculated plants (Fig. 4A). Leaf area was increased by $4.8 \%$ and $12.57 \%$ in $P$. indica inoculated plants at $70 \mathrm{mM}$ and $150 \mathrm{mM} \mathrm{NaCl}$ concentration, respectively as compared to uninoculated plants. PGPB which showed increase in leaf area by $14.78 \%$ and $20.63 \%$ at

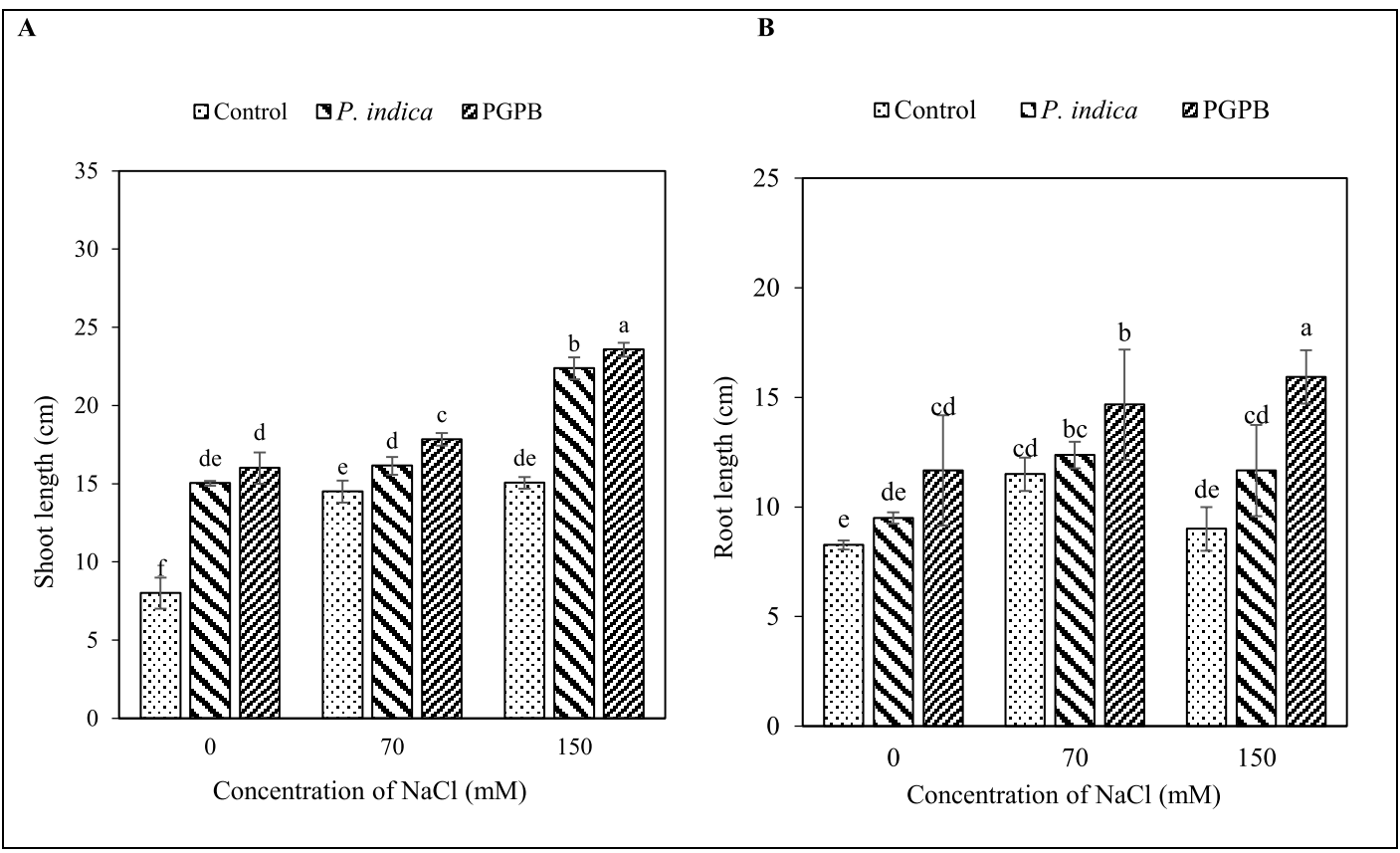

Figure 2: Effects of different concentration of $\mathrm{NaCl}$ on (A) shoot length (B) root length of microbial inoculated and uninoculated T. foenum-graecum plants. 


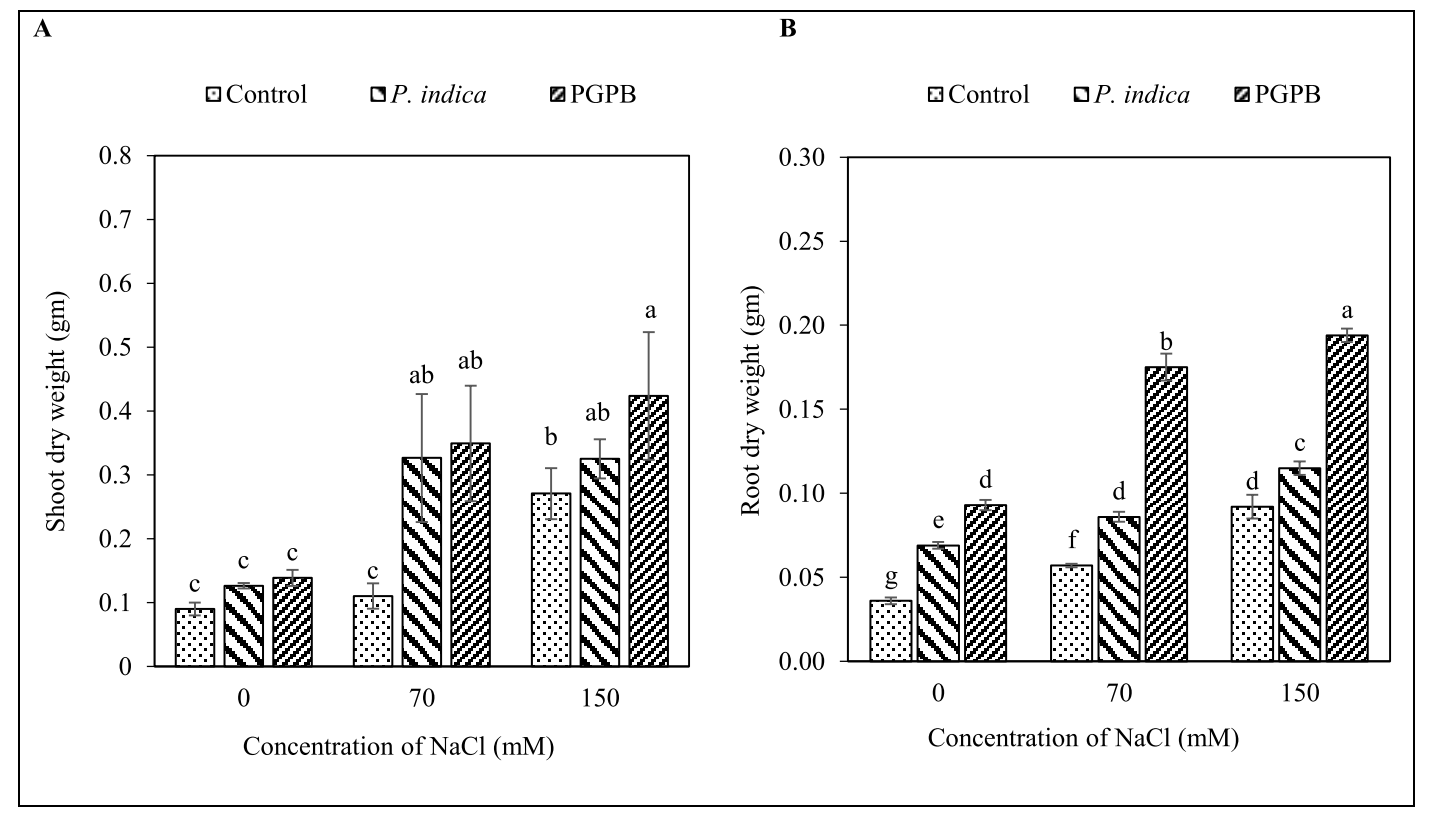

Figure 3: Influence of different concentrations of $\mathrm{NaCl}$ on (A) shoot dry weight (B) root dry weight of microbial inoculated and uninoculated T. foenum-graecum plants.

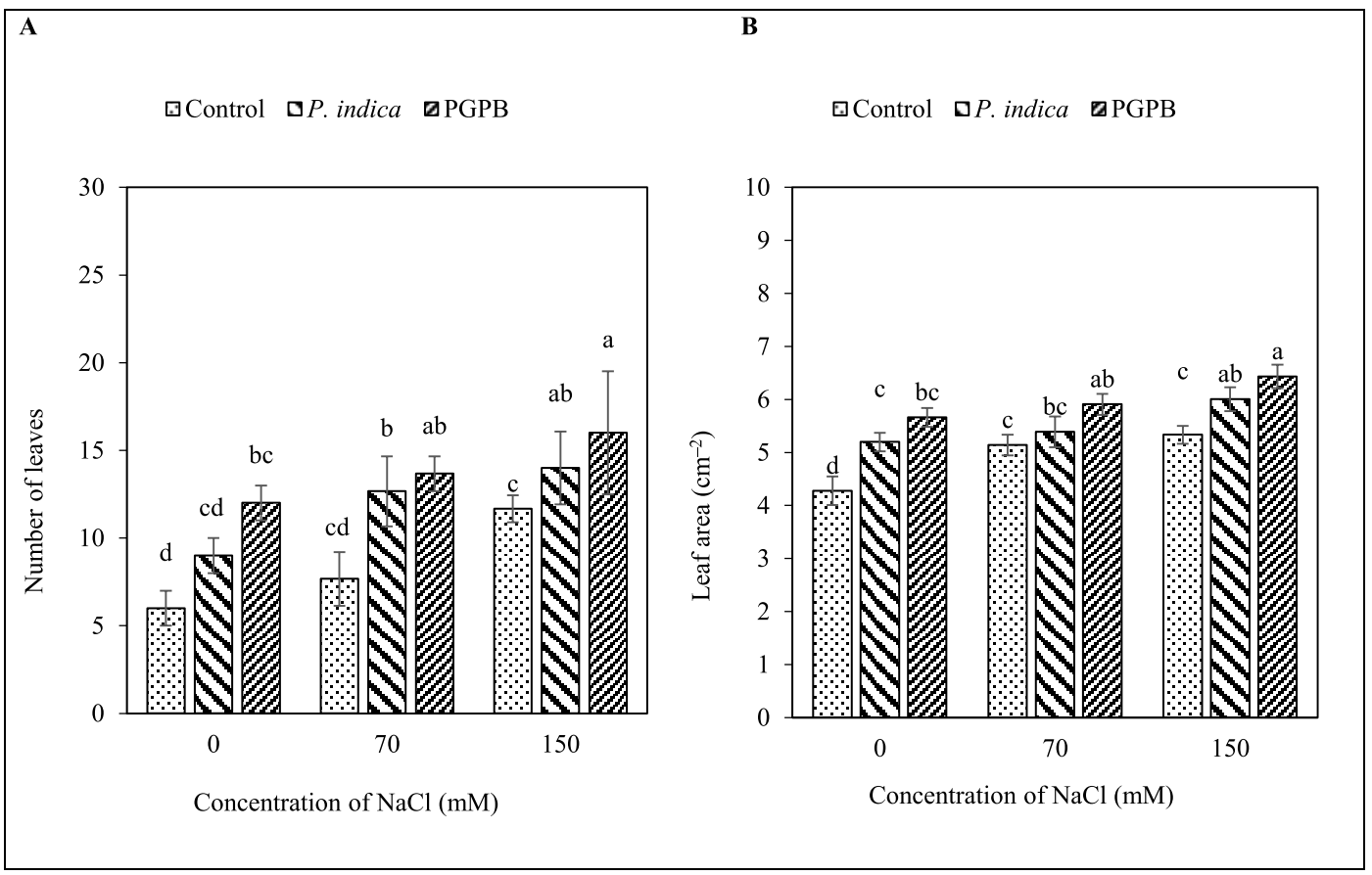

Figure 4: Effects of different concentration of $\mathrm{NaCl}$ (A) number of leaves (B) leaf area of microbial inoculated and uninoculated T. foenum-graecum plants.

$70 \mathrm{mM}$ and $150 \mathrm{mM} \mathrm{NaCl}$ concentration, respectively, as compared to uninoculated plants (Fig. 4B).

\subsection{Photosynthesis Rate, Stomatal Conductance, Transpiration and Internal $\mathrm{CO}_{2}$}

Under salinity condition, there was a significant difference in photosynthesis rate, stomatal conductance, transpiration, and internal $\mathrm{CO}_{2}$ between microbial inoculated and uninoculated plants.
Microbial inoculated plants showed increased photosynthesis rate, stomatal conductance, transpiration, and internal $\mathrm{CO}_{2}$ level as compared to uninoculated plants. However, PGPB inoculated plants showed better results than $P$. indica inoculated plants in terms of photosynthesis rate, stomatal conductance, transpiration, and internal $\mathrm{CO}_{2}$. In PGPB inoculated plants, the photosynthetic rate was significantly increased by $89.81 \%$ and $80.42 \%$ at $70 \mathrm{mM}$ and $150 \mathrm{mM} \mathrm{NaCl}$ concentrations, respectively, as compared to uninoculated plants, whereas $P$. indica inoculated plants showed 


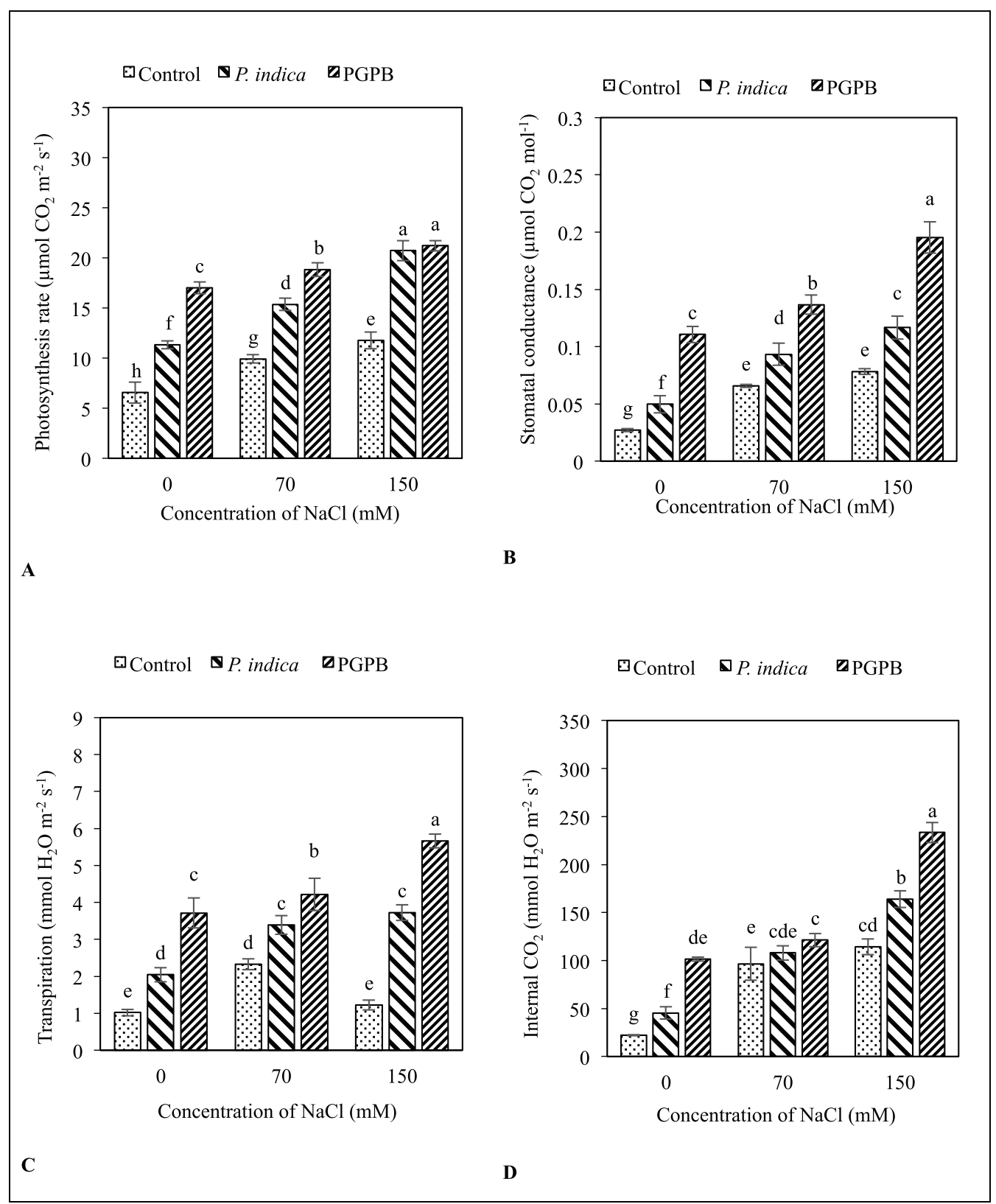

Figure 5: Effects of different concentration of $\mathrm{NaCl}$ on $(\mathbf{A})$ photosynthesis $(\mathbf{B})$ stomatal conductance $(\mathbf{C})$ transpiration $(\mathrm{D})$ internal $\mathrm{CO}_{2}$ of microbial inoculated and uninoculated T. foenum-graecum plants.

an increase by $54.74 \%$ and $76.34 \%$ at $70 \mathrm{mM}$ and $150 \mathrm{mM} \mathrm{NaCl}$ concentrations, respectively as compared to uninoculated plants (Fig. 5A). In PGPB inoculated plants the stomatal conductance was significantly increased by $107.6 \%$ and $150 \%$ at $70 \mathrm{mM}$ and $150 \mathrm{mM} \mathrm{NaCl}$ concentrations, respectively as compared to uninoculated plants, whereas $P$. indica inoculated plants showed an increase by $42.55 \%$ and $49.30 \%$ at $70 \mathrm{mM}$ and $150 \mathrm{mM} \mathrm{NaCl}$ concentrations, respectively, as compared to uninoculated plants (Fig. 5B). In PGPB inoculated plants, the transpiration rate was significantly increased by $81.46 \%$ and $363.9 \%$ at $70 \mathrm{mM}$ and $150 \mathrm{mM} \mathrm{NaCl}$ concentrations, respectively, as compared to uninoculated plants, whereas $P$. indica inoculated plants showed an increase in the transpiration by $46.12 \%$ and $204.9 \%$ at $70 \mathrm{mM}$ and $150 \mathrm{mM} \mathrm{NaCl}$ concentrations, respectively, as compared to uninoculated plants (Fig. 5C). In PGPB inoculated plants, the internal $\mathrm{CO}_{2}$ was significantly increased by $25.79 \%$ and $104.38 \%$ at $70 \mathrm{mM}$ and $150 \mathrm{mM} \mathrm{NaCl}$ concentrations, respectively, as compared to uninoculated plants. The $P$. indica inoculated plants showed an increase in the internal $\mathrm{CO}_{2}$ by $11.9 \%$ and $43.49 \%$ at 70 $\mathrm{mM}$ and $150 \mathrm{mM} \mathrm{NaCl}$ concentrations, respectively, as compared to uninoculated plants (Fig. 5D).

\subsection{Photosynthetic Pigments}

Under salinity stress, there was a significant difference in photosynthetic pigments content between microbial inoculated and uninoculated plants. Microbial inoculated plants showed increased content of photosynthetic pigments as compared to uninoculated plants. However, PGPB inoculated plants showed better results 


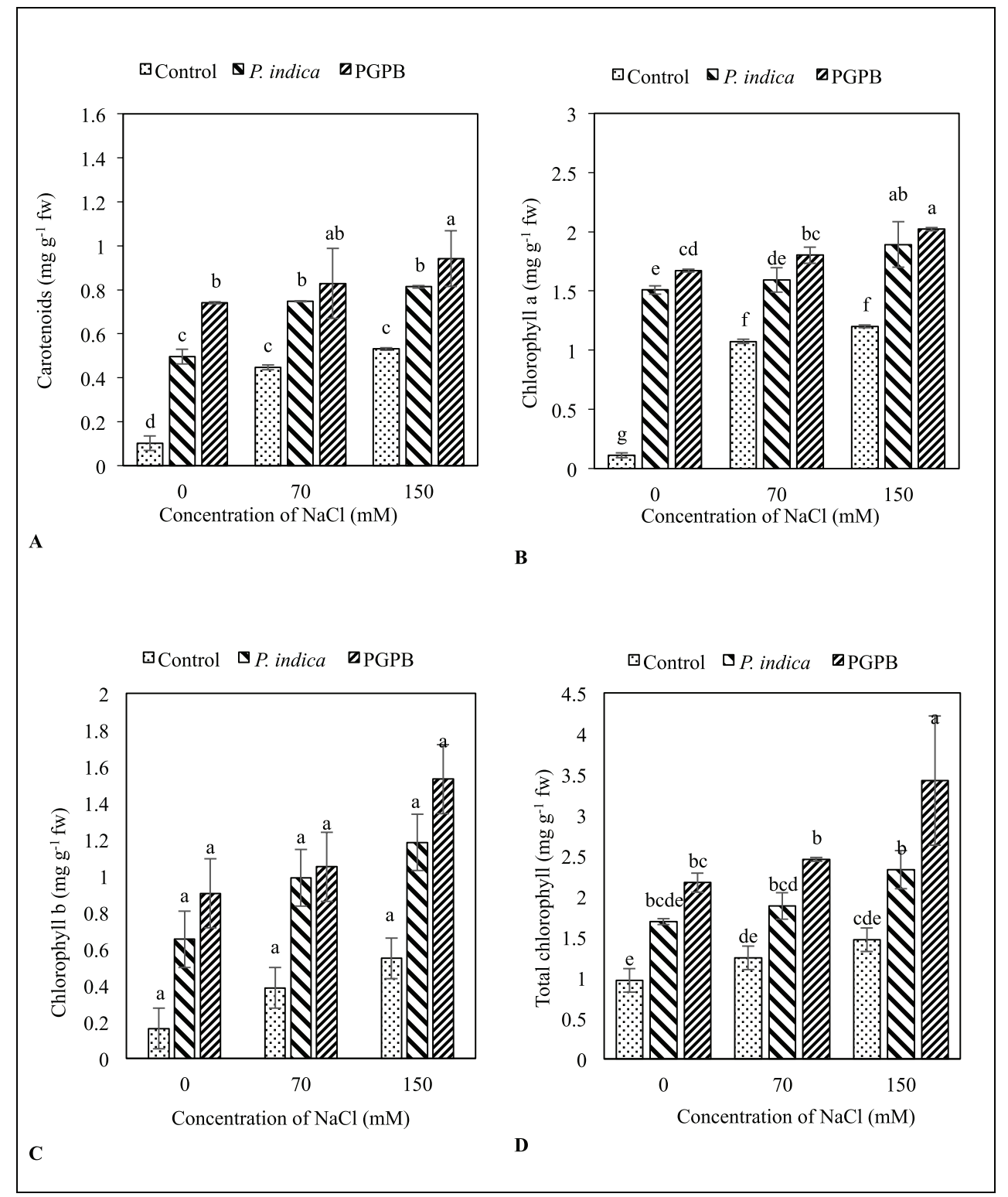

Figure 6: Effects of different concentration of $\mathrm{NaCl}$ on $(\mathbf{A})$ carotenoids $(\mathbf{B})$ chlorophyll a (C) chlorophyll b (D) total chlorophyll content of microbial inoculated and uninoculated T. foenum-graecum plants.

than $P$. indica in terms of content of photosynthetic pigments, viz., chlorophyll a, chlorophyll b, total chlorophyll, and carotenoid. In PGPB, inoculated plants carotenoid content was significantly increased by $86.36 \%$ and $77.35 \%$ at $70 \mathrm{mM}$ and $150 \mathrm{mM} \mathrm{NaCl}$ concentrations, respectively, as compared to uninoculated plants, whereas, $P$. indica inoculated plants showed increase by $68.18 \%$ and $52.83 \%$ at $70 \mathrm{mM}$ and $150 \mathrm{mM} \mathrm{NaCl}$ concentrations, respectively, as compared to uninoculated plants (Fig. 6A). In PGPB inoculated plants, the chlorophyll a content was significantly increased by $68.22 \%$ and $68.33 \%$ at $70 \mathrm{mM}$ and $150 \mathrm{mM} \mathrm{NaCl}$ concentrations, respectively, as compared to uninoculated plants, whereas $P$. indica inoculated plants showed an increase by $48.60 \%$ and $57.50 \%$ at 70 $\mathrm{mM}$ and $150 \mathrm{mM} \mathrm{NaCl}$ concentrations, respectively, as compared to uninoculated plants (Fig. 6B). In PGPB inoculated plants, the chlorophyll $\mathrm{b}$ content was significantly increased by $173.68 \%$ and $183.3 \%$ at $70 \mathrm{mM}$ and $150 \mathrm{mM} \mathrm{NaCl}$ concentration, respectively, as compared to uninoculated plants, whereas $P$. indica inoculated plants showed an increase in the chlorophyll b content by $157.8 \%$ and $103.7 \%$ at $70 \mathrm{mM}$ and $150 \mathrm{mM} \mathrm{NaCl}$ concentrations, respectively, as compared to uninoculated plants (Fig. 6C). In PGPB inoculated plants, the total chlorophyll content was significantly increased by $80.64 \%$ and $134.25 \%$ at $70 \mathrm{mM}$ and $150 \mathrm{mM} \mathrm{NaCl}$ concentrations, respectively, as compared to uninoculated plants, whereas $P$. indica inoculated plants showed an increase in the total chlorophyll content by $51.61 \%$ and $58.90 \%$ at $70 \mathrm{mM}$ and $150 \mathrm{mM} \mathrm{NaCl}$ concentrations, respectively, as compared to uninoculated plants (Fig. 6D).

\subsection{Nitrogen and Protein}

During salinity stress, there was a significant difference in nitrogen and protein content between microbial inoculated and uninoculated plants. Microbial inoculated plants showed increased 


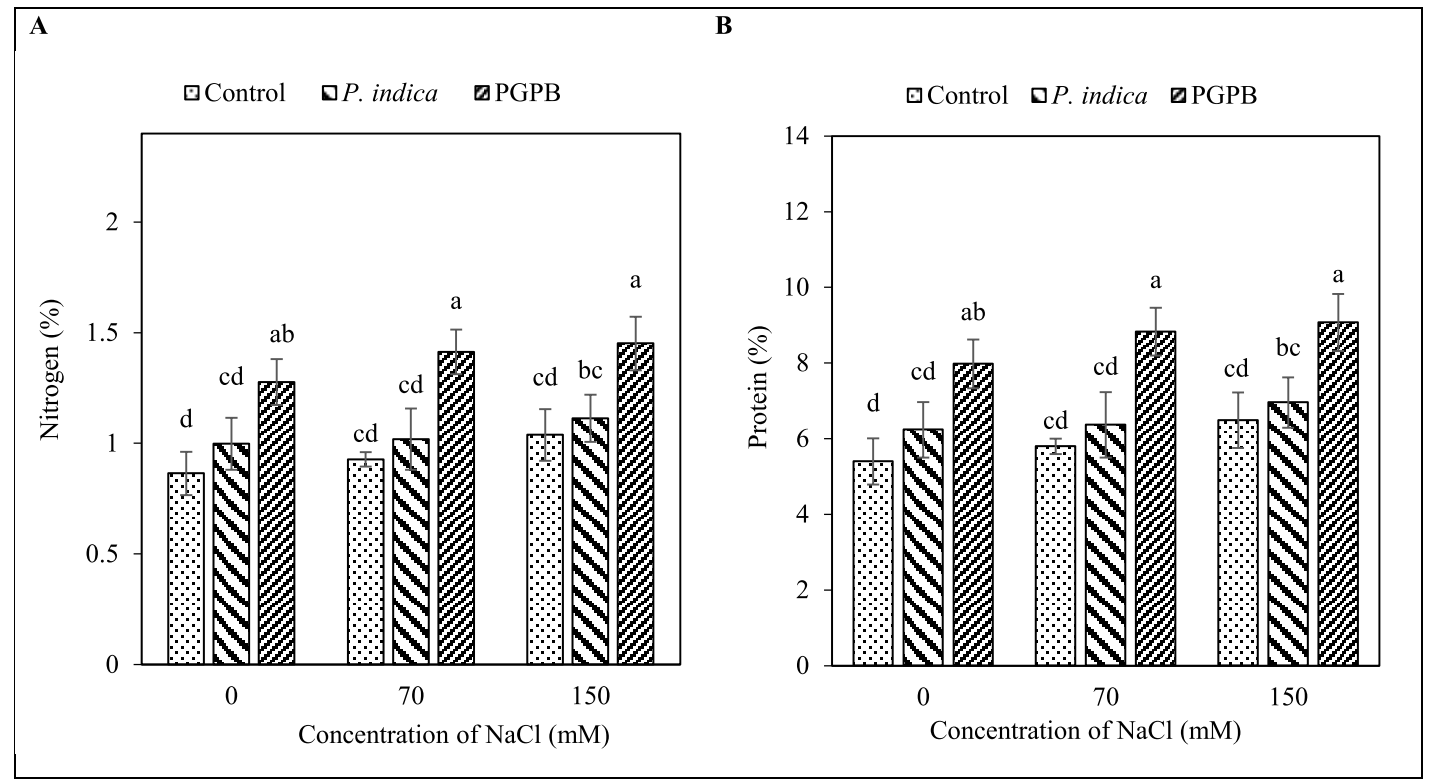

Figure 7: Effect of different concentrations of $\mathrm{NaCl}$ on (A) nitrogen and (B) protein content of microbial inoculated and uninoculated T. foenum-graecum plants.

content of nitrogen and protein as compared to uninoculated plants. However, PGPB inoculated plants showed better results than $P$. indica in terms of nitrogen and protein content. In PGPB inoculated plants, nitrogen and protein content was significantly enhanced by $53.26 \%$ and $40.78 \%$ at $70 \mathrm{mM}$ and $150 \mathrm{mM} \mathrm{NaCl}$ concentrations, respectively, as compared to uninoculated plants, whereas $P$. indica inoculated plants showed an increase by $9.7 \%$ and $7.76 \%$ only at $70 \mathrm{mM}$ and $150 \mathrm{mM} \mathrm{NaCl}$ concentrations, respectively, as compared to uninoculated plants (Fig. 7A and B).

\section{DISCUSSION}

Inoculation with microorganisms had elevated the morphological responses (Fig. $1 \mathrm{~A}-\mathrm{C}$ ) like increased shoot and root length, under high salinity conditions, which was unlike in the uninoculated plants. PGPB showed better results than $P$. indica in increasing root and shoot length (Fig. 2A and B). Increase in the shoot and root length was due to enhanced intake of surplus amount of nutrients like nitrogen and many other essential nutrients, when inoculated with beneficial micro-organisms. Gupta and Pandey [30] have also showed increase in shoot and root length in french beans seedlings under salinity stress when inoculated with the strains of PGPB (ACC02 and ACC06).

Microbial inoculation showed a presented a remarkable result in elevating the shoot and root dry weight as compared to uninoculated plants (Fig. 3A and B). However, the results showed that PGPB inoculated plants had better impact than $P$. indica in elevating the shoot and root dry weight. Elevation in the shoot and root biomass in the microbial inoculation was due to the increase in nitrogen and protein content and photosynthetic rate. Uninoculated plants showed poor results. Increase in the shoot and root dry mass was reported by Hajiboland et al. [31] in Aeluropus littoralis when inoculated with fungi Claroideoglomus etunicatum under salinity stress.

Under salinity stress, there was a significant difference in the number of leaves and leaf area between microbial inoculated and uninoculated plants. Microbial inoculated plants showed significant increase in the number of leaves and leaf area as compared to uninoculated plants (Fig. 4A and B). However, PGPB inoculated plants showed better results than $P$. indica in terms of number of leaves and leaf area. The increase in number of leaves was might due to the division of cells causing change in leaf number. Leaf area was found to be highest in the PGPB inoculation as compared to the $P$. indica inoculation under extreme salinity stress. Leaf area is one of the most important factors which directly co-relates with the photosynthetic active area. Elevation in leaf area was caused because of intake of various inorganic and organic nutrients, water uptake. Khalloufi et al. [32] have showed increase in the number of leaves (leaf count) and leaf area under saline stress when inoculated with fungi Rhizophagus irregularis in Solanum lycopersicum L. plants.

Microbial inoculation was very beneficial as it improved various physiological parameters like photosynthesis rate, stomatal conductance, transpiration, and internal $\mathrm{CO}_{2}$ even under the high salinity stress (Fig. 5 A-D). PGPB inoculated plants showed remarkable results in elevating photosynthetic rate, stomatal conductance, transpiration, and internal $\mathrm{CO}_{2}$ than $P$. indica inoculated plants. Photosynthetic rate was increased in the microbial inoculation even under the high salinity stress because of high leaf area which directly co-relates with the photosynthetic efficiency of plants. Stomatal conductance is a measure of the degree of the stomatal opening and acts as an indicator of plant water status, increase in the stomatal conductance might be due to plantwater relations. Transpiration, on the other hand, was increased due to the increased utilization of water during photosynthesis which created transpiration pull. Increased internal $\mathrm{CO}_{2}$ content enhanced the photosynthesis rate, plant growth and development. Increased internal $\mathrm{CO}_{2}$ was due to increased stomatal conductance. The photosynthetic efficiency was increased in Ocimum basilicum L. when inoculated with arbuscular mycorrhizal fungi (Glomus deserticola) under high salinity stress [33].

There was a significant difference in photosynthetic pigments content between microbial inoculated and uninoculated plants. 
Microbial inoculated plants showed increased content of photosynthetic pigments as compared to uninoculated plants (Fig. 6 A-D). However, PGPB inoculated plants showed better results than $P$. indica in terms of content of photosynthetic pigments viz. chlorophyll a, chlorophyll b, total chlorophyll, and carotenoid. Increased content of photosynthetic pigments might be due to increased uptake of nutrients. Seeds inoculated with Bacillus subtilis and Pseudomonas fluorescens caused significantly increase in the photosynthetic pigments of radish plants under salinity stress [34].

During salinity stress, there was a notable difference in nitrogen and protein content between microbial inoculated and uninoculated plants. Microbial inoculated plants showed increased content of nitrogen and protein as compared to uninoculated plants (Fig. 7 A and B). However, PGPB showed remarkable results in elevating nitrogen and protein than $P$. indica. Nitrogen is a major component of chlorophyll, through which plants uses sunlight and produce sugars and oxygen. Also, nitrogen is the building blocks of the amino acids, increase in the nitrogen content co-related with the increase in protein content in the plants. Protein act as osmolyte maintain the osmotic balance during stress condition. Increased salinity tolerance in fenugreek plant might be due to enhanced production of protein. Nitrogen content was also increased in Acacia saligna (Labill.) under high salinity stress when inoculated with arbuscular mycorrhizal fungi [35].

\section{CONCLUSION}

Piriformospora indica and PGPB inoculated fenugreek plants showed enhanced morphological attributes (shoot and root length, shoot and root dry mass, leaf count, and leaf area) and physiological responses (photosynthesis, stomatal conductance, transpiration, and internal $\mathrm{CO}_{2}$ ) during salinity stress as compared to uninoculated plants. The results presented in this investigation clearly showed that PGPB and $P$. indica improved salt stress tolerance potential of fenugreek plants, by enhanced accumulation of carotenoids, chlorophyll a, chlorophyll b, total chlorophyll, nitrogen, and protein content in plants during salinity stress. The improved physiological and biochemical responses in PGPB and $P$. indica inoculated plants under salinity stress, also indicate that plant-microbe interaction could mitigate salinity stress in fenugreek plant.

\section{ACKNOWLEDGEMENTS}

SB and SS contributed equally to this research work. SB and SS are thankful to Department of Biotechnology, Delhi Technological University for providing the necessary research facilities. The authors are thankful for the Department of Microbiology, IARI, New Delhi for the PGPB inoculum. The authors are thankful for the Department of Microbiology, Amity University, Noida, Uttar Pradesh for the $P$. indica inoculum.

\section{AUTHOR CONTRIBUTIONS}

All authors made substantial contributions to conception and design, acquisition of data, or analysis and interpretation of data; took part in drafting the article or revising it critically for important intellectual content; agreed to submit to the current journal; gave final approval of the version to be published; and agree to be accountable for all aspects of the work. All the authors are eligible to be an author as per the international committee of medical journal editors (ICMJE) requirements/guidelines.

\section{FUNDING}

There is no funding to report.

\section{CONFLICTS OF INTEREST}

The authors report no financial or any other conflicts of interest in this work.

\section{ETHICAL APPROVALS}

This study does not involve experiments on animals or human subjects.

\section{REFERENCES}

1. Zhang S, Fan C, Wang Y, Xia Y, Xiao W, Cui X. Salt-tolerant and plant growth-promoting bacteria isolated from high-yield paddy soil. Can J Microbiol 2018;64(12):968-78.

2. Singh BK, Trivedi P, Singh S, Macdonald CA, Verma JP. Emerging microbiome technologies for sustainable increase in farm productivity and environmental security. Microbiol Aust 2018;39(1):17-23.

3. Jogawat A, Saha S, Bakshi M, Dayaman V, Kumar M, Dua M, et al. Piriformospora indica rescues growth diminution of rice seedlings during high salt stress. Plant Signal Behav 2013;8(10):e26891.

4. Daliakopoulos IN, Tsanis IK, Koutroulis A, Kourgialas NN, Varouchakis AE, Karatzas GP, et al. The threat of soil salinity: a European scale review. Sci Total Environ 2016;573:727-39.

5. Bharti N, Pandey SS, Barnawal D, Patel VK, Kalra A. Plant growth promoting rhizobacteria Dietzia natronolimnaea modulates the expression of stress responsive genes providing protection of wheat from salinity stress. Sci Rep 2016;6:34768.

6. Shilev S. Plant-growth-promoting bacteria mitigating soil salinity stress in plants. Appl Sci 2020;10(20):7326.

7. Tavakkoli E, Rengasamy P, McDonald GK. High concentrations of $\mathrm{Na}^{+}$and $\mathrm{Cl}^{-}$ions in soil solution have simultaneous detrimental effects on growth of faba bean under salinity stress. J Exp Bot 2010;61(15):4449-59.

8. Clarke D, Williams S, Jahiruddin M, Parks K, Salehin M. Projections of on-farm salinity in coastal Bangladesh. Environ Sci Process Impacts 2015;17(6):1127-36.

9. Gupta B, Huang B. Mechanism of salinity tolerance in plants: physiological, biochemical and molecular characterization. Int J Genomics 2014; Article ID: 751596:1-18. http://dx.doi org $/ 10.1155 / 2014 / 701596$.

10. Kumar A, Singh S, Gaurav AK, Srivastava S, Verma JP. Plant growthpromoting bacteria: biological tools for the mitigation of salinity stress in plants. Front Microbiol 2020;11:1216.

11. Carillo P, Annunziata MG, Pontecorvo G, Fuggi A, Woodrow P. Salinity stress and salt tolerance. In: Shanker A, Venkateswarlu B (eds.). Abiotic stress in plants - mechanisms and adaptations. In Tech, London, UK, pp 1:21-38, 2011.

12. Parida AK, Das AB. Salt tolerance and salinity effects on plants: a review. Ecotoxicol Environ Saf 2005;60(3):324-49.

13. Saravanavel R, Ranganathan R, Anantharaman P. Effect of sodium chloride on photosynthetic pigments and photosynthetic characteristics of Avicennia officinalis seedlings. Recent Res Sci Technol 2011;3: 177-80.

14. Hanin M, Ebel C, Ngom M, Laplaze L, Masmoudi K. New insights on plant salt tolerance mechanisms and their potential use for breeding Front Plant Sci 2016;7:1787. 
15. Nongpiur RC, Singla-Pareek SL, Pareek A. Genomics approaches for improving salinity stress tolerance in crop plants. Curr Genomics 2016;17(4):343-57.

16. Carmen B, Roberto D. Soil bacteria support and protect plants against abiotic stresses. In: A. Shaner, Venkateswarlu B (eds.). Abiotic stress in plants mechanisms and adaptations. In Tech, London, UK, pp $143-$ 70, 2012.

17. Meena KK, Sorty AM, Bitla UM Choudhary K, Gupta P, Pareek A, et al. Abiotic stress responses and microbe mediated mitigation in plants: the omics strategies. Front Plant Sci 2017;8:172.

18. Enebe MC, Babalola OO. The influence of plant growth-promoting rhizobacteria in plant tolerance to abiotic stress: a survival strategy. Appl Microbiol Biotechnol 2018;102(18):7821-35.

19. Siddikee MA, Chauhan PS, Anandham R, Han GH, Sa T. Isolation, characterization and use for plant growth promotion under salt stress, of ACC deaminase-producing halotolerant bacteria derived from coastal soil. J Microbiol Biotechnol 2010;20(11):1577-84.

20. Wang W, Wu Z, He Y, Huang Y, Li X, Ye BC. Plant growth promotion and alleviation of salinity stress in Capsicum annuum L. by Bacillus isolated from saline soil in Xinjiang. Ecotoxicol Environ Saf 2018;164:520-9.

21. Chen L, Liu Y, Wu G, Veronican NK, Shen. Q, Zhang N, et al. Induced maize salt tolerance by rhizosphere inoculation of Bacillus amyliliquefaciens SQR9. Physiol Plant 2016;158(1):34-44.

22. Krishnamoorthy R, Kim K, Subramanian P, Senthilkumar M, Anandham R, Sa T. Arbuscular mycorrhizal fungi and associated bacteria isolated from salt-affected soil enhances the tolerance of maize to salinity in coastal reclamation soil. Agric Ecosyst Environ 2016;231:233-9.

23. Kang SM, Radhakrishnan R, Khan AL, Kim MJ, Park JM, Kim BR, et al. Gibberellin secreting rhizobacterium, Pseudomonas putida $\mathrm{H}-2-3$ modulates the hormonal and stress physiology of soybean to improve the plant growth under saline and drought conditions. Plant Physiol Biochem 2014;84:115-24.

24. Shukla PS, Agarwal PK, Jha B. Improved salinity tolerance of Arachis hypogaea (L.) by the interaction of halotolerant plant-growth promoting rhizobacteria. J Plant Growth Regul 2012;31(2):195-206.

25. Bano A, Fatima M. Salt tolerance in Zea mays (L.) following inoculation with Rhizobium and Pseudomonas. Biol Fertil Soils 2009;45(4):405-13.

26. Hassani D, Khalid M, Huang D, Zhang YD. Morphophysiological and molecular evidence supporting the augmentative role of Piriformospora indica in mitigation of salinity in Cucumis melo L. Acta Biochim Biophys Sin (Shanghai) 2019;51:301-12.
27. Ahmad A, Alghamdi SS, Mahmood K, Afzal M. Fenugreek a multipurpose crop: potentialities and improvements. Saudi J Biol Sci 2016;23(2):300-10.

28. Hiscox JD, Israelstam GF. A method for the extraction of chlorophyll from leaf tissue without maceration. Can J Bot 1979;57(12):1332-4.

29. Islam MS, Haque MM, Hossain MS. Estimation of moisture and crude protein content of locally available raw materials for poultry feed. Int J Pharm Sci Res 2015; 6(5):1900-1906.

30. Gupta S, Pandey S. ACC deaminase producing bacteria with multifarious plant growth promoting traits alleviates salinity stress in french bean (Phaseolus vulgaris) plants. Front Microbiol 2019;10:1506.

31. Hajiboland R, Dashtebani F, Aliasgharzad N. Physiological responses of halophytic C4 grass, Aeluropus littoralis to salinity and arbuscular mycorrhizal fungi colonization. Photosynthetica 2015;53(4):572-84.

32. Khalloufi M, Martínez-Andújar C, Lachaâl M, Karray-Bouraoui N, Pérez-Alfocea F, Albacete A. The interaction between foliar GA3 application and arbuscular mycorrhizal fungi inoculation improves growth in salinized tomato (Solanum lycopersicum L.) plants by modifying the hormonal balance. J Plant Physiol 2017;214:134-44.

33. Elhindi KM, El-Din AS, Elgorban AM. The impact of arbuscular mycorrhizal fungi in mitigating salt-induced adverse effects in sweet basil (Ocimum basilicum L.). Saudi J Biol Sci 2017;24(1):175-9.

34. Mohamed HI, Gomaa EZ. Effect of plant growth promoting Bacillus subtilis and Pseudomonas fluorescens on growth and pigment composition of radish plants (Raphanus sativus) under $\mathrm{NaCl}$ stress. Photosynthetica 2012;50(2):263-72.

35. Soliman AS, Shanan NT, Massoud ON, Swelim DM. Improving salinity tolerance of Acacia saligna (Labill.) plant by arbuscular mycorrhizal fungi and Rhizobium inoculation. Afr. J. Biotechnol 2014;11:1259-66.

\section{How to cite this article:}

Bisht S, Singh S, Singh M, Sharma JG. Augmentative role of Piriformospora indica fungus and plant growth promoting bacteria in mitigating salinity stress in Trigonella foenumgraecum. J Appl Biol Biotech 2022; 10(01):85-94. 